\title{
How Swiftly does Re-Victimisation Occur? Evidence from Surveys of Victims
}

Dainis Ignatans, University of Huddersfield

\section{Abstract}

The observation that victimisation raises the probability of subsequent victimisation is well established. That repeat crimes tend to happen quickly is important in the preventive utility of the phenomenon. However, the time decay curve of repeat victimisation is conventionally studied using police recorded crime data, making it susceptible to alternative explanations by confounding actual victimisation with rates of victim report to the police. The present paper reports an attempt to use victimisation survey data to demonstrate decay curves. The analyses show that households experiencing a high frequency of repeat victimisation experience repeats much sooner than households where repeats occur fewer times. Subsequent repeats take place ever more quickly after the preceding one. Quick victimisation is perceived to be increasingly serious the sooner it occurs.

\section{Introduction}

Crime concentration may be thought of in many ways, demographic, (for example with victimisation unevenly distributed by age, wealth or gender (Ignatans and Pease, 2015)), spatial (by street connectivity or the presence of 'attractive nuisances' (Trickett et al. 1992)) and temporal (by time of day, day of week and scheduled sports fixtures). Concentration is, in many senses, the police's friend and the citizen's enemy insofar as certain places and times cannot be avoided. This point will be developed below. 
Historically, police deployment has been informed by local knowledge augmented by whatever 'intelligence' and local priorities may be communicated to officers at shift briefings. Over the last two decades, there has developed a vogue for predictive patrolling, based primarily upon analyses of the spatio-temporal patterning of crime (see for a review Perry et al. 2013). Three related strands of research feed predictive patrolling practice. First, there is the demonstration of the high incidence of repeat victimisation, i.e. victimisation against the same target (see Farrell and Pease 2017). Complementing this is Weisburd's law of crime concentration (Weisburd, 2015). While the law holds in demonstrating a small proportion of places hosting a high proportion of crime, these are not always the same places (Haberman et al, 2016). Third, related to the phenomenon of repeat victimisation but extending it, is the demonstration of risk contagion (Bowers et al 2004), i.e. that there is a time and distance limited elevation of risk after victimisation. Of particular interest is the (perhaps unsurprising) demonstration of short time periods between incidents of domestic violence where victim and perpetrator cohabit (Mele 2009).

While the emphasis on predictive patrolling has moved from direct repeats to near repeats, it is contended here (and see Ignatans and Pease 2018) that a renewed interest in direct repeats would afford some advantages as the starting point for prevention-oriented police action. There are signs that in the United Kingdom, the Office of National Statistics is taking a renewed interest in repeat victimisation, specifically in connection with analysis of the national victimisation survey, the Crime Survey for England and Wales. ${ }^{1}$ 
The time decay curve of risk of repeat victimisation, in which short-run repeats predominate, is ubiquitously observed in police recorded crime data (see Mele (2009) for a too little known example for partner violence), and in offender accounts of burglary and vehicle crime (Ashton et al. 1998). The present paper seeks to determine whether the same curve may also be discernible from victimisation surveys, tested here using the Crime Survey for England and Wales. To attempt this is important because the time-limited need for place-focused preventive action renders the prevention of repeats a more viable and attractive prevention tactic. Insofar as problems in the interpretation of victimisation surveys differ from the problems of police recorded crime data, similarities between them in time decay curves offer a kind of triangulation which potentially clarifies what is actually happening. This point will be developed in the discussion section of this paper.

There are several practical obstacles to such a demonstration. A few are listed here.

1. Shortcomings in victim memory preclude the precise placement of victimisations in past time.

2. Conventions mean that details of series of events are not captured because to do so would take victim interview duration beyond what is affordable.

3. The recall period for repeat crimes is truncated because it begins only at the date of the earlier victimisation. For example, assuming the calendar year as the recall period for a first victimisation, if a crime occurs at the end of June, there is only a six-month recall period for the second.

Given these difficulties, and to stress the point made earlier, it is worthwhile to see if there is the risk decay effect from victimisation survey data because to do so would demonstrate that it is not an artefact of the police recording process. Early studies of 
the time course of repeat victimisation using police recorded crime data were flawed by an absence of attention to the time window effect, i.e. the fact that taking data from a truncated period, as described above, will spuriously elevate the proportion of repeats that happen quickly. Taking a ridiculous example, using crimes from a onemonth period will overstate short run repeats by excluding all precursor events and all repeats of index events after the month has elapsed. The size of the time window effect self-evidently falls as the length of the period from which index crimes are extracted increases. Farrell et al. (2002) have quantified the time window effect. Put briefly, the question of whether short run repeats still predominate after the time window effect has been taken into account.

\section{Methodology}

Data used here come from Crime Survey for England and Wales (CSEW). Formerly known as the British Crime Survey, this is a cross-sectional victimisation survey providing data on crime victimisation and related experiences, gleaned from a representative sample of people aged 16 and above in England and Wales. First

rolled out in 1981, the survey is now conducted by the Office for National Statistics. It has been carried out annually since 2000 . CSEW employs a cluster sampling method in order to ensure greater inclusivity of England and Wales' diverse demography. For the purposes of this paper two sweeps of CSEW (2011-2012 and 2014-2015) were used. The central purpose was to study time elapsing between victimisation events against the same person or household. In CSEW, those reporting some victimisation in the screener questions of the main form, completed by all respondents, were included here. Respondents thereby identified as having suffered some victimisation(s) are invited to complete up to six forms. Each completed form contains data about either a single event or the most recent event in 
a series of similar crimes in similar circumstances presumably by the same perpetrator. Each such form includes the month in which the event occurred (for single events) or the month in which the most recent event occurred (for series events). Events which fall outside the designated recall period or which turn out not to have been crimes may thus be identified and excluded from further analysis.

For present purposes, the last incident from series events is treated as a single incident, there being no way of knowing the months in which earlier events in the series took place. Households were grouped by the number of victim forms completed. Households suffering repeat victimisation were identifiable as those for which two or more victim forms had been completed and were flagged as repeat victim households. Average time lags in months between the first and second, second and third, and every subsequent pair of victimisations were calculated. The decision to use the mean as the preferred measure of central tendency can be justified by the maximum possible month range being 11, so extreme outliers would not distort the picture.

Some limitations of the data for the purpose to which they are used here should be made explicit.

1. Telescoping within the designated recall period is not detectable so may overstate the frequency of quick repeats.

2. CSEW allows for only 6 event forms per household, prioritising the most serious events. Therefore, the time lags between events reported by households with 6 forms may not represent the true picture, as other victimisation incidents would be omitted from the time sequence. This would 
not strongly affect the overall results, with less than $2 \%$ of households reporting 6 victimisations in the datasets explored.

3. Recorded crime data analyses would allow for an exploration of repeats over a more flexible timescale, however would not permit the individualised characteristics of crime seriousness to be analysed, therefore CSEW is prioritised.

4. Because series events are treated as the single most recent event, where one or more of the forms represents a series, some repeat victimisation is not analysed.

5. Supporting the analyses with qualitative data would contextualise the findings, but the author feels would take away from the practical focus of time lag analyses.

\section{Analyses}

Sooner and sooner...

Incidents are analysed, first without differentiating individual offence types, thereafter separate analyses for property and personal victimisation were conducted. While much of the repeat victimisation literature distinguishes crime types, the resulting small numbers would preclude meaningful interpretation.

Figure 1 represents average time lags between repeated victimisation incidents for the year 2011, that is, the time it takes before a subsequent incident. Households are split into groups by the maximum number of victimisations experienced (for example the 4+ group being households that experienced either four, five or six victimisations). Two main findings must be taken from this figure. 
First, the average time lag between the earliest incidents is shorter the more of the incidents there are to come, i.e. the more quickly a second event occurs after a first, the more subsequent events there are likely to be. Pause to consider this in light of the recognition that towards the end of the recall period, necessarily only short interval repeats will appear in the dataset. Essentially this means that there may be missed events after the end of the recall period, but that the gaps between events within the recall period can be interpreted, subject to assumptions about consistent memory across the recall period. Furthermore, the problem presented by series events tends to make the visual impression less dramatic, since necessarily excluding gaps between events within a series and within the recall period would reduce the inter-event gaps represented.

Households that experienced more victimisations began to experience the repeats much sooner than those who do not. In one sense this is self-evident in that high rate victims have more events to be 'squeezed into' the recall period, i.e. high rate victims are victimised more frequently. The time lag between the first and second victimisation incidents for households experiencing $2+$ events is roughly 3.4 months, so, the first repeat comes in 3.4 months after the first for all households where repeats occur. The same time lag is merely 2.6 months for households experiencing $3+$ events, so, leaving out the households with just one repeat decreases the average time until the first incident by 0.8 months. This time lag is further reduced to 2.3 for households experiencing $4+$ events and is just slightly more than 2 months for those victimised five or more times. The same pattern applies for every other pair of incidents - the second repeat comes faster for those who will experience more than just three repeats. So, while the time lag between the second and third events is 2.4 months for households victimised three or more times, it is merely 1.8 for those who 
were to be victimised at least another time, and 1.4 for those victimised $5+$ times. Households experiencing higher frequency of victimisation incidents begin to experience this unfortunate 'chain' of events much quicker than households with fewer repeat incidents.

Of greater interest is the slope of the curves. Every subsequent repeat is experienced sooner than the previous one and this is further amplified by the frequency of victimisation. For example, households experiencing at least one repeat $(2+)$ experienced the first repeat in 3.4 months on average, second repeat in 2.5 months, third repeat in 1.9 months, fourth in 1.7 and fifth in just 1.2 months. Households that have experienced at least three repeats (4+ group) experience the first repeat in 2.3 months, second and third repeat in further 1.8 months each and the fourth incident is experienced 1.7 months after. Not only does every subsequent victimisation come sooner than the previous one, this is also sped up by the frequency of victimisations experienced.

The critic will argue that this result is an artefact of the progressive exclusion of longer term repeats as the end of the recall period gets closer. The writer here contends that the emphasis here should be placed on victimisations that did happen within the time period rather than excluded events after the recall period. If the number of prior victimisations were not a strong predictor of a quick follow up victimisation, the lines should be parallel. The reader is invited to consider subsequent graphs in the same way, without further comment from the writer. 
Figure 1. Time lag between all victimisation incidents in months, 2011

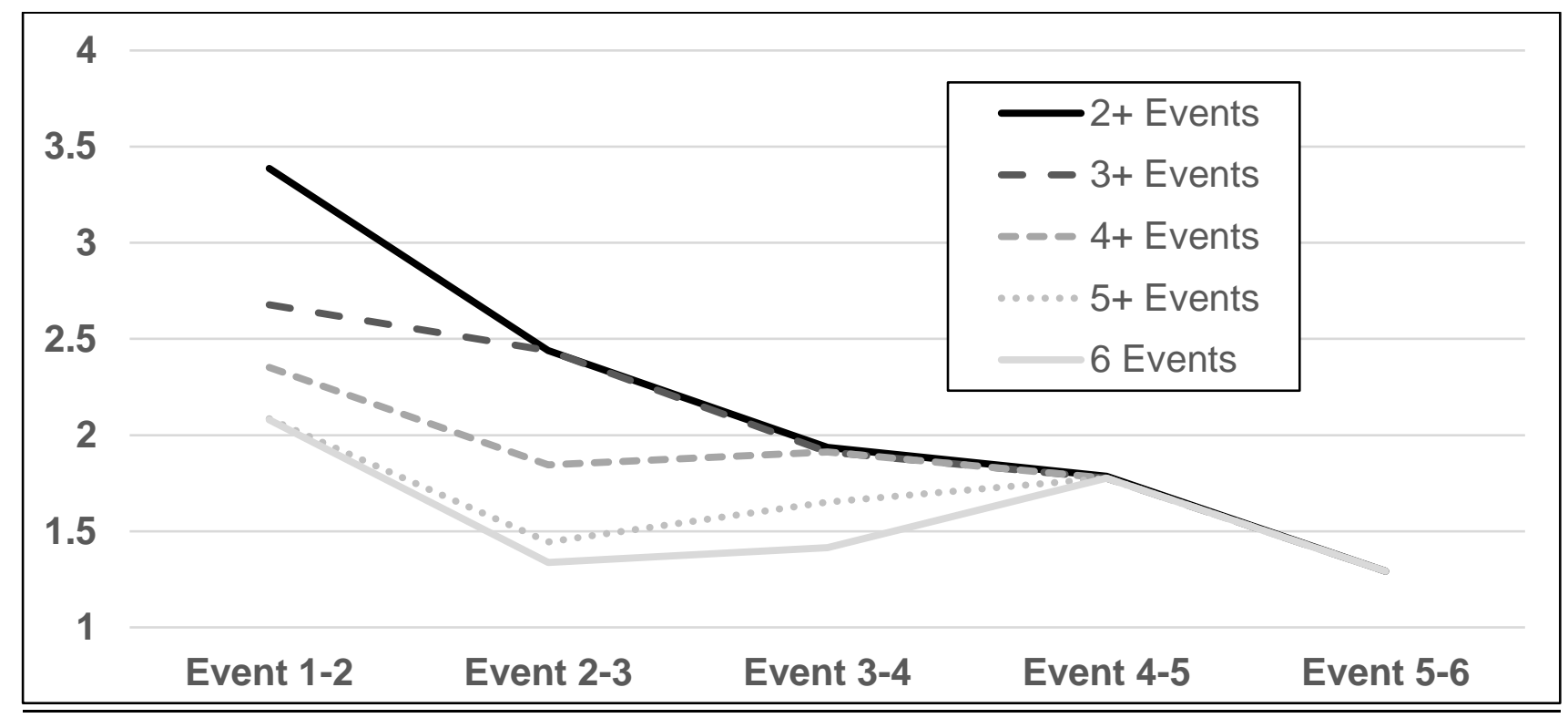

Sample sizes:

\begin{tabular}{|l|l|l|l|l|l|}
\hline Group & 2+ Events & 3+ Events & 4+ Events & 5+ Events & 6 Events \\
\hline $\mathrm{N}$ & 2672 & 838 & 313 & 136 & 65 \\
\hline
\end{tabular}

For the purposes of the next two figures, victimisation incidents were split between property and personal categories. Figure 2 includes all incidents that involve either damage to or theft of possessions (including motor vehicles). Figure 3 included all victimisation where a person was undoubtedly in the vicinity of the event occurring and experienced the event first hand, such as threats, domestic violence and theft from the person. 
Figure 2. Time lag between property and vehicle victimisation incidents in months, 2011

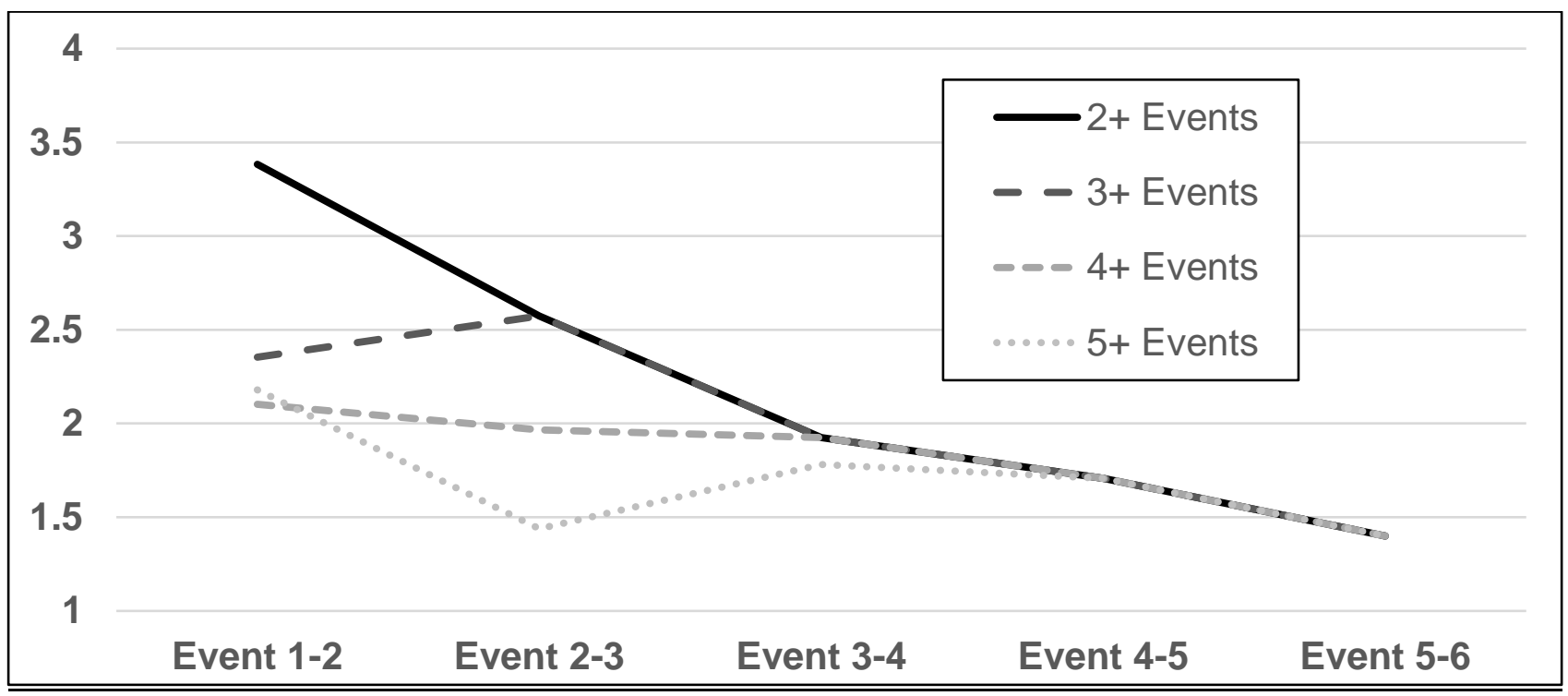

Sample sizes:

\begin{tabular}{|l|l|l|l|l|}
\hline Group & 2+ Events & 3+ Events & 4+ Events & 5+ Events \\
\hline $\mathrm{N}$ & 1699 & 435 & 119 & 41 \\
\hline
\end{tabular}

The same two findings, by and large, apply to property (Figure 2) and personal (Figure 3) victimisations. First, the early repeats occur much quicker in households that are to experience a greater number of further victimisations. The time lag between the first and second property victimisations is 3.4 months on average for all households victimised repeatedly (2+ group), yet merely 2.3 months for those who were victimised three or more times. Second, the subsequent events generally occur faster than the earlier repeats. For personal victimisation, the first repeat for the repeatedly victimised households in general $(2+)$ comes 3.3 months after the first incident, yet the second repeat is just two months away, and the third is likely to occur in 1.7 months. 
Figure 3. Time lag between personal victimisation incidents in months, 2011

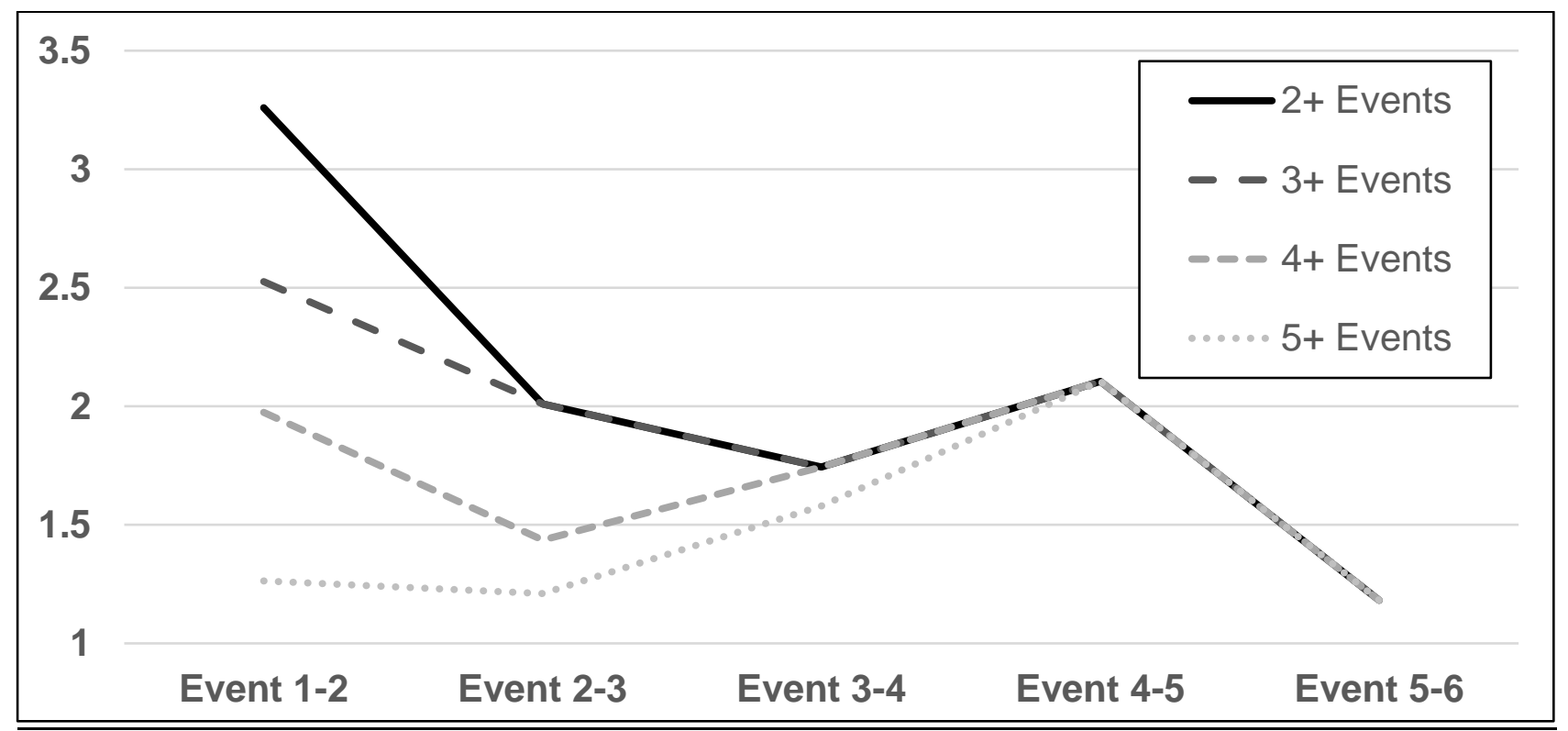

Sample sizes:

\begin{tabular}{|l|l|l|l|l|}
\hline Group & 2+ Events & 3+ Events & 4+ Events & 5+ Events \\
\hline $\mathrm{N}$ & 429 & 99 & 40 & 20 \\
\hline
\end{tabular}

In order to compare whether the repeat victimisation time patterns have changed over time, data from CSEW sweep of $2015 / 16$ is depicted below in an identical fashion. 
Figure 4. Time lag between all victimisation incidents in months, 2015

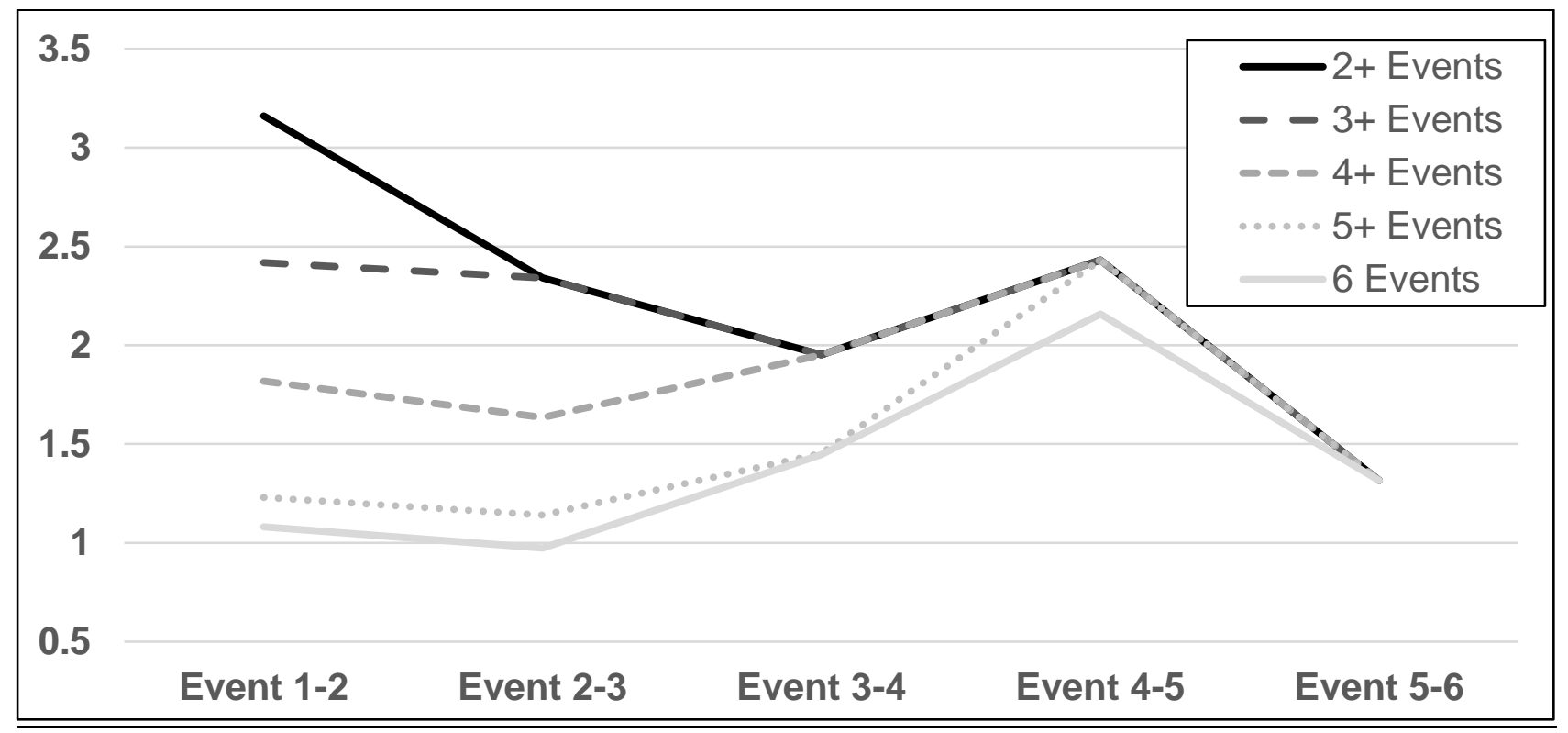

Sample sizes:

\begin{tabular}{|l|l|l|l|l|l|}
\hline Group & 2+ Events & 3+ Events & $4+$ Events & $5+$ Events & 6 Events \\
\hline $\mathrm{N}$ & 1363 & 403 & 143 & 65 & 38 \\
\hline
\end{tabular}

Figure 5. Time lag between property and vehicle victimisation incidents in months, 2015

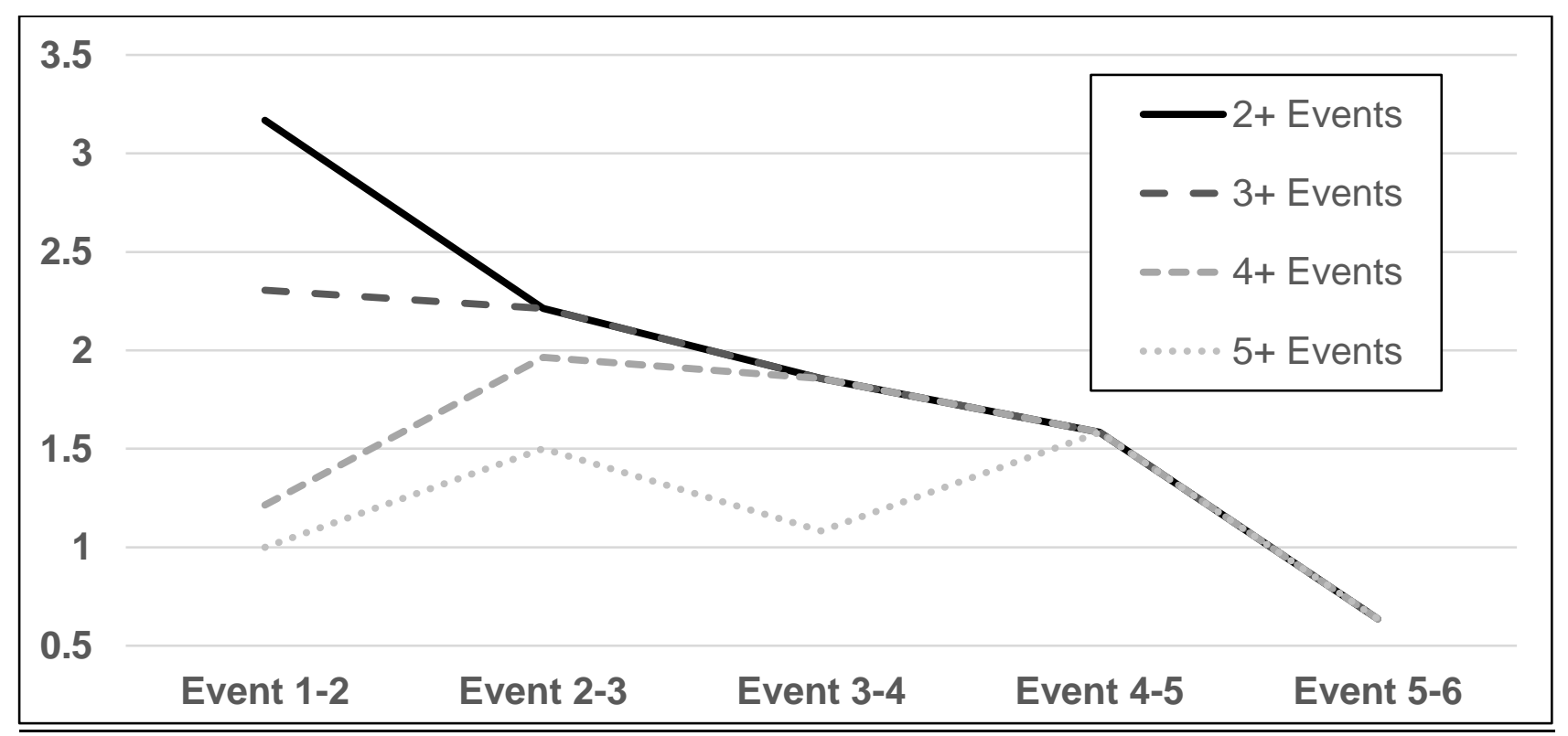

Sample sizes:

\begin{tabular}{|l|l|l|l|l|}
\hline Group & 2+ Events & 3+ Events & 4+ Events & 5+ Events \\
\hline $\mathrm{N}$ & 838 & 191 & 53 & 19 \\
\hline
\end{tabular}


Figure 6. Time lag between personal victimisation incidents in months, 2015

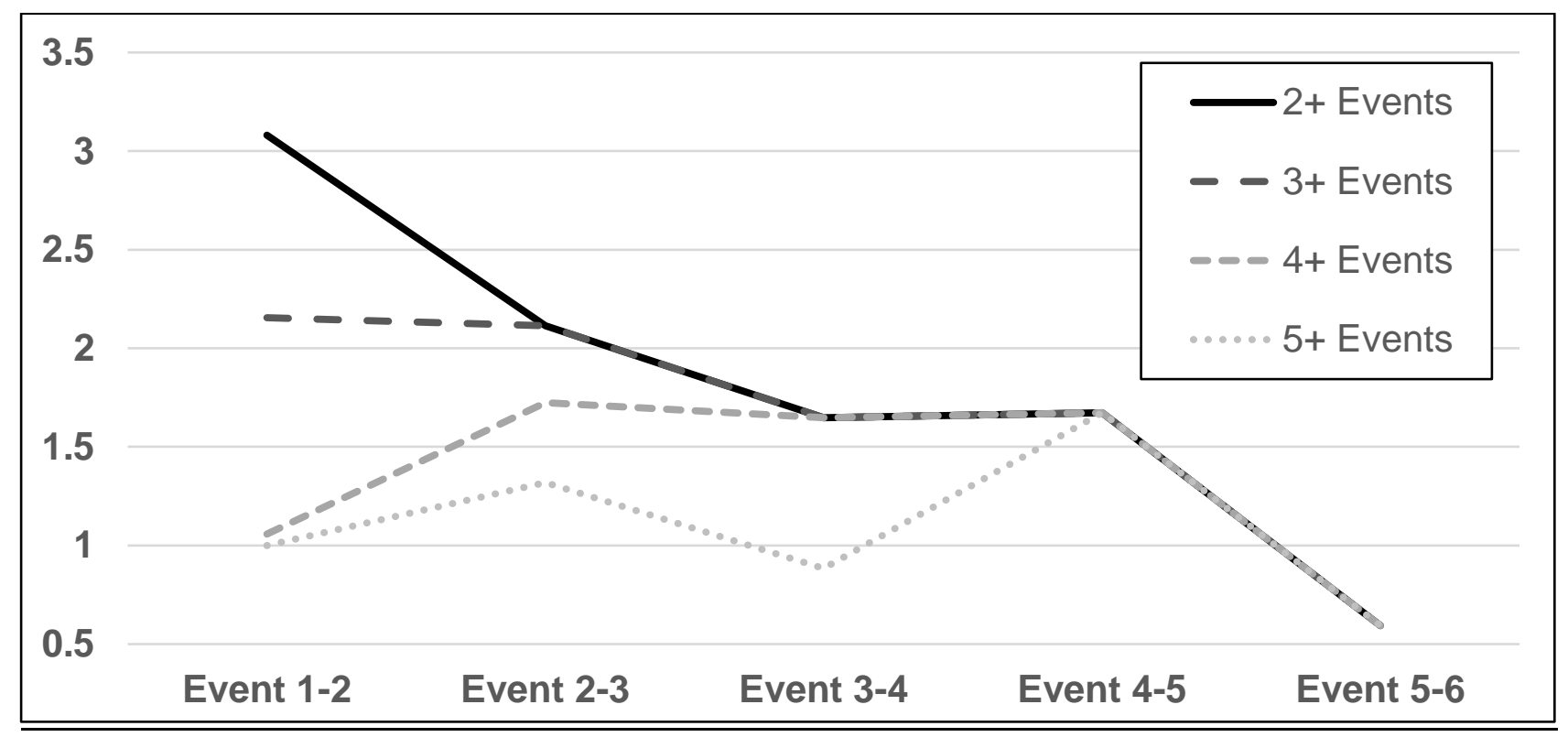

Sample sizes:

\begin{tabular}{|l|l|l|l|l|}
\hline Group & 2+ Events & 3+ Events & 4+ Events & 5+ Events \\
\hline $\mathrm{N}$ & 238 & 61 & 28 & 12 \\
\hline
\end{tabular}

What can be seen from the comparison is that the same patterns apply for the 2015/16 sweep as for the 2011/12 sweep, yet the timescales are reduced throughout the sample. This indicates that now households experience the early repeats even sooner, compared to five years back and the time lags between every subsequent incident are even shorter.

It is important to note that it is impossible to check for victimisation which may have taken place prior to CSEW sweep, therefore what is viewed as the first event in CSEW may have been preceded with other victimisation incidents. However, this issue merely impacts the accuracy of numerical values in the analyses. The hypothesis remains unaffected. Even if a number of the incidents treated as first incidents here are already repeats, they will be earlier repeats than the next incident in line (if what we see as the first incident is already the third incident, our perceived second incident will therefore be the fourth incident). So, while this would unfairly 
widen the time lags between expected re-victimisation (mistaking a time lag between 3-4 incidents as time lag between 1-2 incidents), this would not affect the reality of the incidents becoming more condensed with increased frequency.

Sooner now than before...

For an easy comparison, the numerical time lags between first and second victimisation incidents and the changes in them are depicted for years 2011 and 2015 in Table 1. below.

Table 1. Comparison of the time lags in months between CSEW sweeps of 2011 and 2015 for households experiencing all repeat victimisation (2+).

\begin{tabular}{|l|l|l|l|l|}
\hline & \multicolumn{2}{|l|}{2011} & 2015 & \\
\hline & $\begin{array}{l}\text { Average } \\
\text { Time Lag } \\
(\text { months) }\end{array}$ & $\begin{array}{l}\text { Compared to } \\
\text { Index(100) - 6 Events }\end{array}$ & $\begin{array}{l}\text { Average } \\
\text { Time Lag } \\
\text { (months) }\end{array}$ & $\begin{array}{l}\text { Compared to } \\
\text { Index(100) - 6 Events }\end{array}$ \\
\hline $\begin{array}{l}2+ \\
\text { Events }\end{array}$ & 3.39 & 162.87 & 3.16 & 292.36 \\
\hline $\begin{array}{l}3+ \\
\text { Events }\end{array}$ & 2.68 & 128.77 & 2.42 & 223.60 \\
\hline $\begin{array}{l}4+ \\
\text { Events }\end{array}$ & 2.35 & 113.11 & 1.82 & 168.12 \\
\hline $\begin{array}{l}5+ \\
\text { Events }\end{array}$ & 2.08 & 100.25 & 1.23 & 113.73 \\
\hline $\begin{array}{l}6 \\
\text { Events }\end{array}$ & 2.08 & & 1.08 & \\
\hline
\end{tabular}

Two key points are to be taken from this table. There is a notable reduction in time lag between repeated victimisation both between the sweeps (repeats happen sooner in 2015 than in 2011 if compared each with each) and within the sweeps (time gaps between subsequent repeats in 2015 are much shorter than in 2011). To explain those points statistically, the initial repeat victimisation is experienced even 
earlier now than before (3.39 down to 3.16) and every subsequent victimisation is experienced even sooner (2.68 down to 2.42 for second repeat, 2.35 down to 1.82 for fourth, and so on). Secondly, the time lag before the fourth repeat in 2011 was $39 \%$ shorter than for the first repeat (3.39 months for first repeat and 2.08 for fourth repeat), while in 2015 the time lag for the fourth repeat was $61 \%$ shorter using the same comparison (3.16 for first repeat and 1.22 for fourth). So, to put it simply, not only are victims "hit" by the first repeat in a particularly short period of time and faced with repeat victimisation increasingly sooner, the subsequent events happen with a downwards spiralling trajectory.

\section{A peek into seriousness...}

Another question this paper intends to explore is the seriousness of victimisation, which tends to be concentrated within the repeat victimised (Ignatans and Pease, 2016). If the repeat incidents that come sooner are viewed as more serious, this would further amplify the need for prevention of such repeats in line with the first section of the paper. CSEW allows examination of crime seriousness (or crime harm, as the terms are often used interchangeably) through asking its respondents for a seriousness rating of their victimisation experience, from 1 to 20 (20 being most serious). While a subjective measure, deeper investigations into the measure have showed consistency between the ratings of victimisations of similar personal and offender characteristics (Los, Ignatans and Pease, 2017). For the purposes of Figure 7, using the CSEW sweep of 2015/16 four calculations were created to explore how the seriousness of victimisations varies depending on the time it has taken from previous incident. 
In order to explore whether repeated victimisation is rated as less or more serious the sooner it occurs, average seriousness scores were calculated for all repeat victimisations happening with a time lag of up to 12 months. These are presented alongside average seriousness scores of first repeats. In order to see whether the perceived seriousness of victimisations changes more depending on the time it takes for a repeat to occur, the change in seriousness score compared to previous incident for overall victimisation is also displayed alongside the change in seriousness score from the initial victimisation for first repeats.

Figure 7. Time lag between personal victimisation incidents in months and difference in crime seriousness, 2011

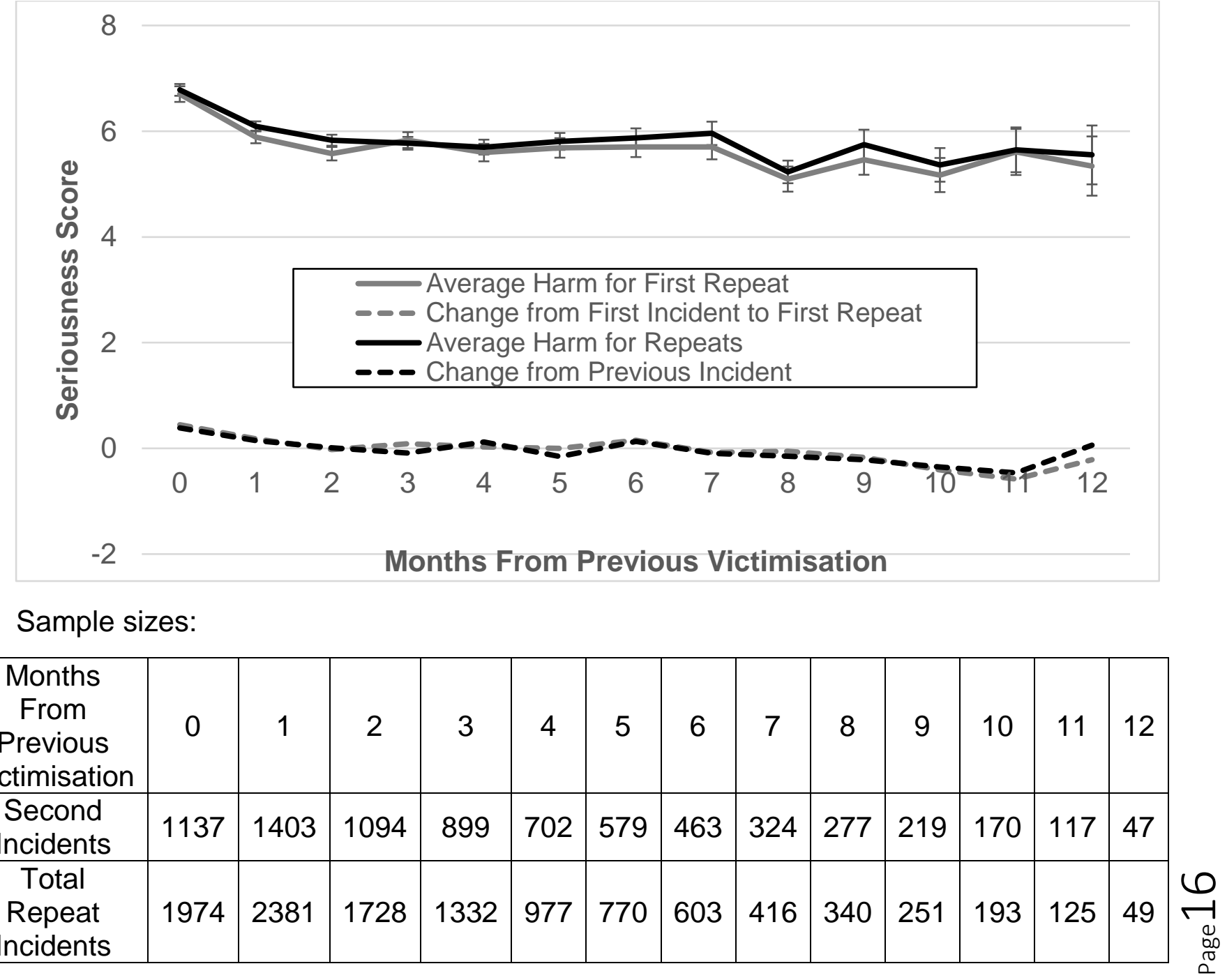


Two key points are to be taken from Figure 7. First, repeat victimisation in general, as well as the first repeats, are perceived as more serious by the victims the sooner they take place. While repeats that occur in the same month as the previous incident are rated on average as 6.9 , a score of only 5.6 is given if the repeat occurs 12 months apart. First repeats are judged as less serious the longer it takes for them to occur ( 6.8 for 0 months down to 5.3 for 12 months). Second, overall repeats and second repeats in particular are judged as increasingly more serious, compared to the previous incident, the sooner they occur. Overall seriousness scores increased by 0.4 for repeats that occurred in the same month as the previous incident, yet were consistently judged as less serious than the previous incidents if they occurred more than 6 months apart.

Survival analysis...

Previous analyses focus upon examining victimisations that have been reported to CSEW. The following analysis incorporates information about households that may or may not have experienced future victimisation incidents after the interview had been conducted, using Kaplan-Meier Survival Analysis. Survival analysis allows examination of 'events' and 'censored' cases, former being incidents that occurred and the latter being cases where information became no longer available past a certain point.

Using CSEW sweep of 2015/16, time windows between either the first and the second victimisation (events), or time windows between the first victimisation and interview (censored cases) were input for all households which have completed a victim form. A survival plot was produced for all victimised households. It is estimated that roughly 10 per cent of households are re-victimised in a matter of the 
first month, with further months accounting for less than three per cent of households each. This overwhelmingly demonstrates that even when the unknown cases are included in the analysis in order to overcome the issues time window poses, it remains clear that repeat victimisations are most likely to occur shortly after the initial incident.

Survival plots for households victimised twice and those victimised multiple times were produced alongside in order to compare estimated time lag prior to victimisation in households where event was reported and are displayed in Figure 8. These demonstrate that 49 per cent of households victimised more than two times experience the second victimisation in a matter of just two months with 24 per cent occurring in the first month after the initial incident. 48 per cent of households victimised only twice experience the second repeat in a matter of three months.

Figure 8. Survival analysis of repeat victimisation in households victimised two times and more than two times, 2015

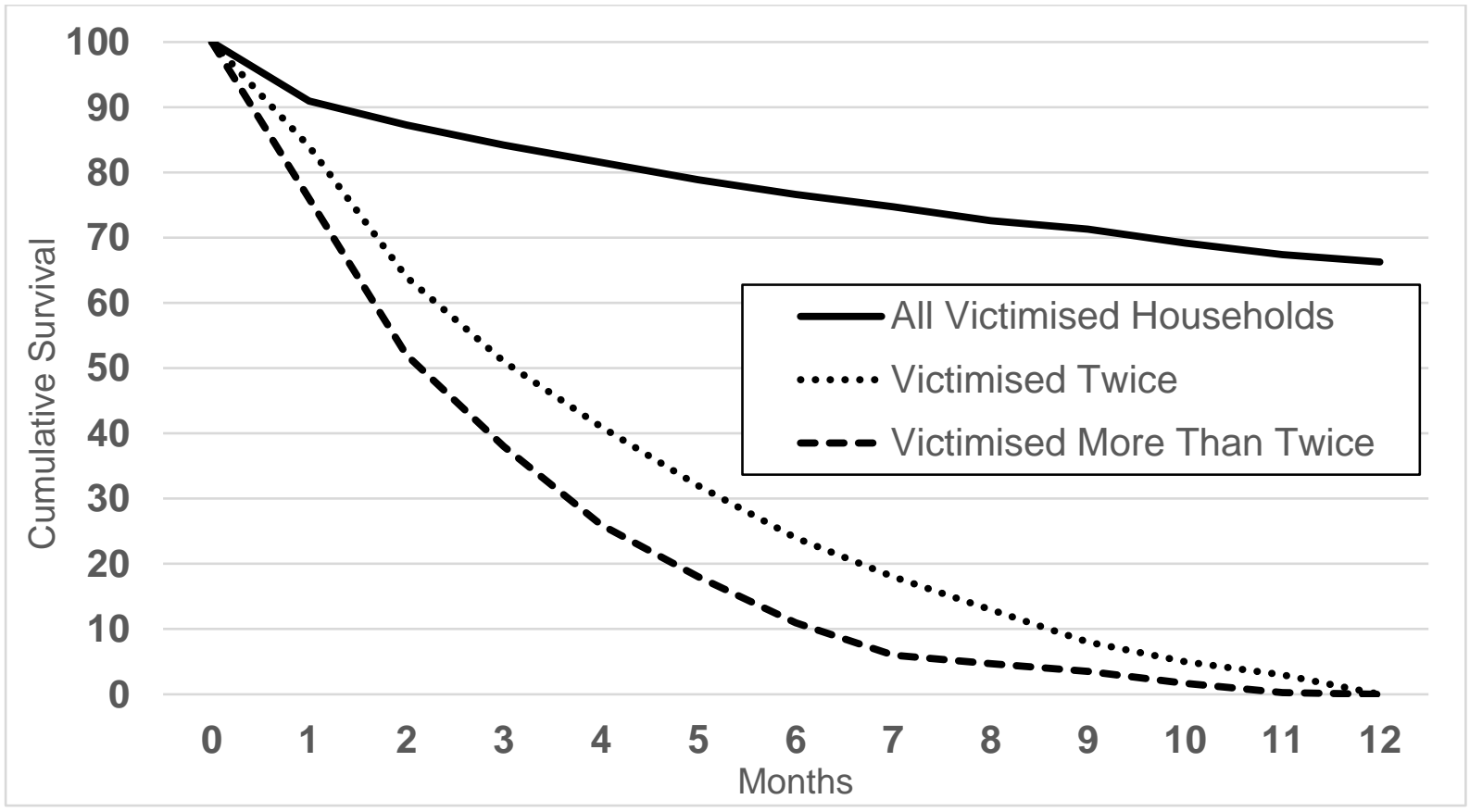




\section{Implications}

The central and important conclusion of the present paper is that analysis of a dataset other than police recorded crime and offender accounts yields a similar picture in that it stresses the shortness of time between victimisations, and how intervals become progressively shorter as the number of prior victimisations increases. It has as a bonus the identification of the relationship between repeat victimisation and seriousness of the offence as assessed by the victim. The appearance that short-run repeats are more frequent in the later CSEW sweep suggests that high rate victims are accounting for a higher proportion of the total crime landscape than hitherto. While suggestions for further research are set out below, the policing implications of the contents of this paper are difficult to overstate. The anticipation of short run repeats is that targeted policing attention in the wake of a crime is a very fruitful prevention and detection tactic. It does not require indefinite attention. It responds to the 'slipperiness of hot spots'. It is centred on victim assessment of the seriousness of the harm they have suffered.

A follow up paper is envisaged in which reporting to the police is looked at alongside the variables deployed for the current analysis. Developments of the work presented here should include the following.

1. A replication of Trickett et al. (1992) should refresh our understand of the proportion of all crime accounted for by high rate (short interval) victims.

2. An analysis of cross-type repeats could enable the identification of policing tactics suited to the specific risks presented for recent victims. 
3. Calculation of seriousness of offences currently not reported to the police will clarify latent demand for police services. Patterns of reporting are currently a mixture of offence seriousness and personal attributes of the reporting victim. Teasing out the contributions of these two elements will be of importance in managing demands on policing services equitably.

It would be interesting to look at other victimisation surveys using a panel approach to check comparability of results and to apply Monte Carlo estimation techniques to demonstrate starkly how far from random is the extent and time decay of victimisation. 


\section{References}

Ashton, J., Brown, I., Senior, B., \& Pease, K. (1998). Repeat Victimisation: Offender Accounts. International Journal of Risk, Security and Crime Prevention, 3(4), 269279.

Bowers K., Johnson S.D. and Pease K. (2004) Prospective Hotspotting: 'The Future of Crime Mapping?' British Journal of Criminology, 44, 641-658.

Farrell ,G. and Pease K. (2017) ‘Preventing Repeat and Near Repeat Crime Concentrations'. In N. Tilley and A. Sidebottom (Eds.). (2017) Handbook of Crime Prevention and Community Safety, 2nd Edition. London: Routledge

Farrell, G., Sousa W. H. and Weisel D. L. (2002). 'The time-window effect in the measurement of repeat victimization: a methodology for its measurement and an empirical study' Crime Prevention Studies, 13, 15-27. (ISSN: 1065-7029).

Haberman, C.P., Song E.T., and Ratcliffe J.H. (2016). Assessing the Validity of the Law of Crime Concentration across Different Temporal Scales. Journal of Quantitative Criminology. https ://doi.org/10.1007/s1094 0-016-9327-4.

Ignatans, D. and Pease K. (2015) Distributive justice and the crime drop. In: Andresen M. and Farrell G. (eds) The Criminal Act: Festschrift for Marcus Felson. London: Palgrave Macmillan, 77-87. 
Ignatans, D. and Pease, K. (2016) Taking Crime Seriously: Playing the Weighting Game. Policing: a Journal of Policy and Practice, 10 (3). pp. 184-193. ISSN $1752-$ 4520

Los, G., Ignatans, D., \& Pease, K. (2017). First-generation immigrant judgements of offence seriousness: evidence from the crime survey for England and Wales. Crime Prevention and Community Safety, 19(2), 151-161.

Mele, M. (2009). The time course of repeat intimate partner violence. Journal of Family Violence, 24(8), 619-624.

Pease, K., Ignatans, D., \& Batty, L. (2018). Whatever happened to repeat victimisation?. Crime Prevention and Community Safety, 20(4), 256-267.

Perry, W. L. (2013). Predictive policing: The role of crime forecasting in law enforcement operations. Rand Corporation.

Trickett, A., Osborn, D. R., Seymour, J., \& Pease, K. (1992). What is different about high crime areas?. The British Journal of Criminology, 32(1), 81-89.

Weisburd, D. (2015). The law of crime concentration and the criminology of place. Criminology, 53(2), 133-157. 